\title{
Statistical Analysis on Nutritional Status and its Associated Factors of Under Five Years Children in Nepal
}

\author{
Upadhyay H.P ${ }^{1,2 *}$, Bhusal $\mathbf{M}^{1}$ \\ ${ }^{1}$ Department of Statistics, Tribhuvan University, Nepal \\ ${ }^{2}$ Department of Community Medicine, College of Medical Science, Bharatpur-10, Chitwan.
}

doi: https://doi.org/10.21467/ajgr.2.1.12-24

* Corresponding Author email:

hpchalise@gmail.com

Article History

Received: 27 February 2017

Revised: 6 March 2017

Accepted: 16 March 2017

Published: 17 March 2017

Student(s)

- Upadhyay H.P

Academic Year: 2015-16, II ${ }^{\text {nd }}$ Semester

Course Level: Master Degree

Course Name: Master in Statistics

Course year: $2^{\text {nd }}$ Year / IV ${ }^{\text {th }}$ Semester

$\operatorname{Mentor}(\mathrm{s})$

- Bhusal M

\begin{abstract}
Malnutrition among under five year of age group is a major underlying cause of the child morbidity and mortality in many developing countries like Nepal. Nutritional status of children is a proxy indicator for assessing the health status of entire population. This study was carried out to evaluate the nutritional status of the most vulnerable age group of children (0-59 months) and to identify different factors associated with it. Generally three anthropometric indicators were often used to assess the nutritional status of children height-for-age, weight-for-height and weight-for-age. This study is based on data of Nepal Demographic and Health Survey. WHO Anthro software and IBM SPSS 20 were used to analyze the data. The prevalence of the malnutrition (stunted, wasted and underweight) was found in the different aspect. This study consists of 2334 children of under five years age groups, out of this $50.9 \%$ were male children and $49.1 \%$ were female children, the prevalence of the stunted is $41 \%$, wasted $29 \%$ and underweight $11 \%$. The prevalence of diarrhea during the data collection period is $13.80 \%$ and prevalence of fever during the data collection period is $18.70 \%$. The statistically significant factor were body mass index of mother, wealth index, size of child at birth and education of mother and smoking habit of mother. Malnutrition (stunted, wasted and underweight) still remains as a major health problem in our country Nepal. So, our government should be focused on those factors which are significantly associated with malnutrition like health care during pregnancy period, education of mother etc. Significant number of under-five children's of Nepal was malnourished. Maternal factors have significant association with nutritional status of the children which include extra diet in pregnancy and lactation, iron supplements in pregnancy, exclusive breast feeding for six months.
\end{abstract}

Keywords: Nutritional status, Malnutrition, Stunted, Wasted, Underweight 


\section{Introduction}

Nepal is a landlocked country between India and China. Nepal is among the poorest countries in the world, $25.2 \%$ percent of the population lives below the poverty line and ranks of $157^{\text {th }}$ out of 187 countries [1]. Malnutrition is a major public health and nutrition problem in Nepal. It is a major underlying cause of the child morbidity and mortality in Nepal [1-3]. Nutrition is the sum of total process involved in utilization of food substance with growth, repair and maintenance of body accomplished. It is the organic process by which an organism assimilates food and uses it for growth and maintenance. Nutrition is the utilization of food to grow, repair and maintain our body and also getting the right amount of nutrients from healthy foods in the right combination. Nutrition has special significance in countries with disadvantages in socioeconomic and hygienic standards. Growth and development of human beings are influenced by genetic and environmental factors. Nutritional status of children is important because it determines their health status, physical growth, development and their academic performance in their life [2]. Nutritious foods are essential for all age but their need is higher during childhood especially under five years of age for growing [3]. Good nutrition combined with regular exercise is concerned with a good health and poor nutrition leads to reduced immunity, increases susceptibility to disease which reduces the productivity. Under nutrition is a condition in which there is inadequate consumption, poor absorption or excessive loss of nutrients. It is a major modifiable and powerful element in promoting health, preventing and treating disease and improving the quality of life. Nutritional status is a key indicator of health assessment [4]. An ideal nutritional status occurs when the supply of nutrients conforms to the nutritional requirements or needs. Good nutrition is the cornerstone for survival, health and development of the country [3-4].

\section{Operational Definition}

\subsection{Anthropometric Measurements}

Anthropometric measurements were carried out to access the degree of malnutrition in children under 5 years of age from all below minus two standard deviation units $(<-2 \mathrm{SD})$.

\subsection{Stunted}

Children of aged 0 to 59 months having the index value for height for age below minus two standard deviation units $(<-2 \mathrm{SD})$.

\subsection{Wasted}

Children of aged 0 to 59 months having the index value for weight for height below minus two standard deviation units $(<-2 \mathrm{SD})$.

\subsection{Underweight}

Children of aged 0 to 59 months having the index value for weight for age below minus two standard deviation units $(<-2 \mathrm{SD})$.

\subsection{Overweight}

Children of aged 0 to 59 months having the index value for weight for age, over two standard deviation units $(>2 \mathrm{SD})$.

\subsection{Birth Weight of Baby}

Birth weight less than $2.5 \mathrm{~kg}$ (2500 gram) was considered as low birth weight and birth weight equal to or more than $2.5 \mathrm{~kg}$ was considered as normal weight (NDHS, 2011). 
Upadhyay et al., Adv. J. Grad. Res.; Vol. 2, Issue 1, pp: 12-24, July 2017

\subsection{Maternal Height}

The height of mother less than $145 \mathrm{~cm}$ was considered as low height and height greater than or equal to 145 $\mathrm{cm}$ was considered as normal height (NDHS, 2011) [6].

\subsection{Body Mass Index (BMI)}

Body mass index is defined as weight in kilogram of the individual divided by the square of the height in the meter, which is used to determine the nutrition status of the mother. $\left\{<18.5 \mathrm{~kg} / \mathrm{m}^{2}\right.$ Underweight $\},\{18.5$ $24.99 \mathrm{~kg} / \mathrm{m}^{2}$, Normal $\} \&\left\{\geq 25 \mathrm{~kg} / \mathrm{m}^{2}\right.$ Overweight $\}$.

\subsection{Sampling Methods}

NDHS had taken the data beginning from 2 February 2011 and the fieldwork was completed on 14 June 2011. For the survey country is broadly divided into three horizontal zones namely mountain, hill and terai. Vertically the country is divided into five development regions. The cross-section of these zones and regions result in 15-eco development regions, which are referred to in the NDHS as sub regions.

\section{Methods Used in Data Analysis}

The data was analyzed by using descriptive and inferential statistics. In the descriptive statistics, different tools such as frequency distribution, bar diagram, pie-chart, percentage diagram were used to show the nutritional status of the children. In bivariate analysis, to test the significance of association between dependent variable (nutritional status) and independent variables (associated factors), Chi-square test was used. Odds ratio and its confidence interval was also calculated to examine strength of association between the variables and its limit. Only for those variables which were statistically significant in bivariate analysis, binary logistic regression was performed to examine the net effect of each independent variable on the nutritional status. Logistic regression was carried out by taking nutritional status as a dependent variable and other significant factors as independent variables. Three logistic regression models were performed separately for stunted, wasted and underweight respectively. P-values less than 0.05 were considered as significant (level of significance 5\%). If p-value $>$ level of significance $(\alpha=0.05)$ then corresponding $\mathrm{H}_{\mathrm{o}}$ was accepted otherwise rejected.

\section{Result and Analysis}

\subsection{Prevalence of Malnutrition}

Figure 1 shows that the prevalence of malnutrition in the children. This study shows that $27.03 \%$ children had some kind of malnutrition (stunted, wasted and underweight) in Nepal [6].

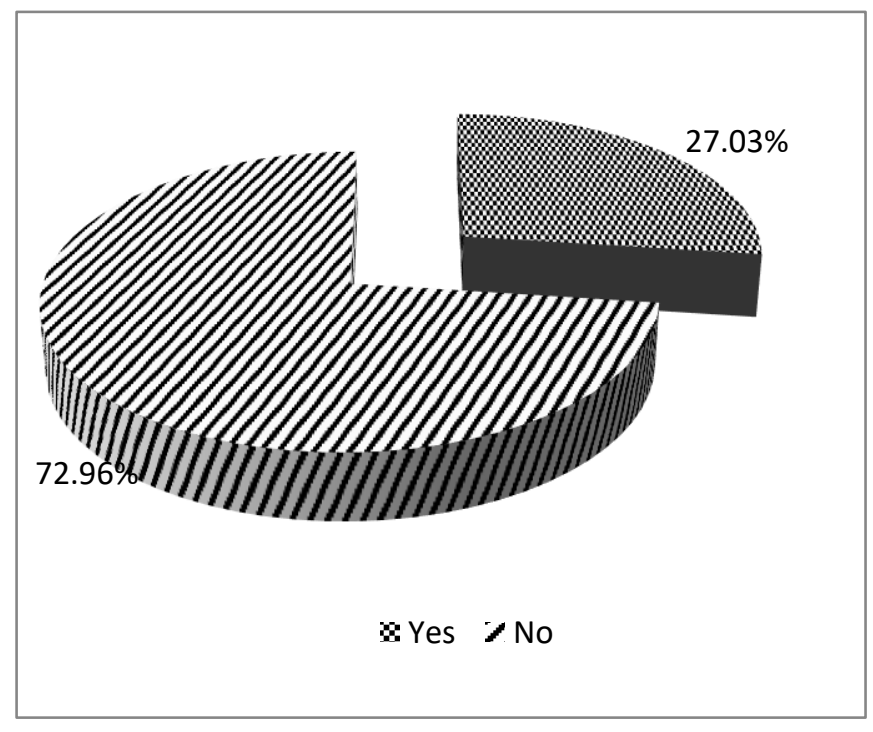

Figure 1: Pie-diagram showing the Prevalence of malnutrition 


\subsection{Prevalence of Malnutrition by Different Characteristics}

Figure 2 shows the prevalence of nutritional status of under five year children. The finding showed that $41 \%$ children were stunted. Similarly, $29 \%$ were underweight and $11 \%$ were wasted [6].It shows that prevalence of malnutrition (Stunting, wasting and underweight) is still major health problems among children of under 5 years, in Nepal. Effective strategies such as community based regular growth monitoring, nutritional counseling and referral mechanism should be adopted by health workers to control these problems.

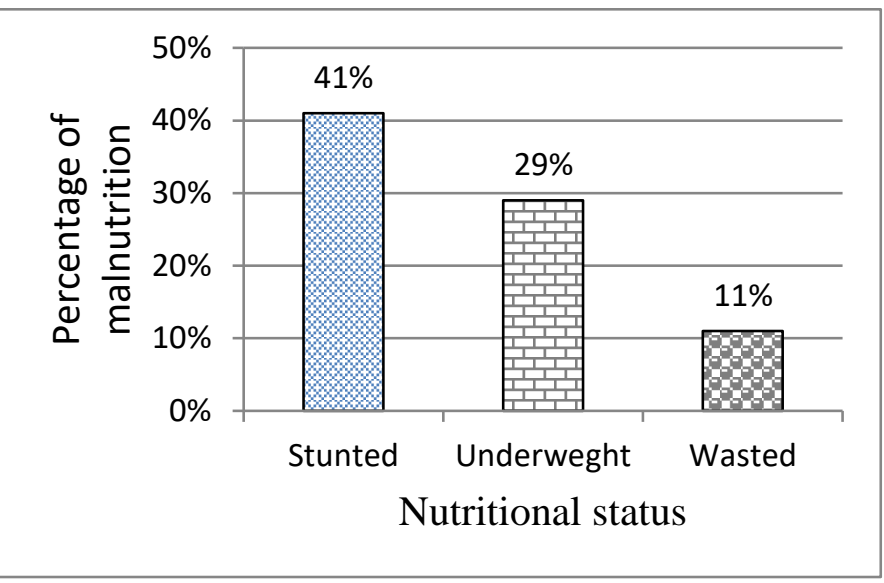

Figure 2: Prevalence of nutritional status of under five year children

\subsection{Prevalence of Malnutrition by Gender Wise}

Figure 3 shows that the prevalence of nutritional status of male and female children. Findings showed that $41.40 \%$ of the male children were stunted, $29.30 \%$ of the male children were underweight and $12.60 \%$ were wasted. Similarly, $39.50 \%$ of the female children were stunted, $28 \%$ were underweight and $9.79 \%$ were wasted [6]. Which shows that male children were more likely to have all type of malnutrition as compare to female children.

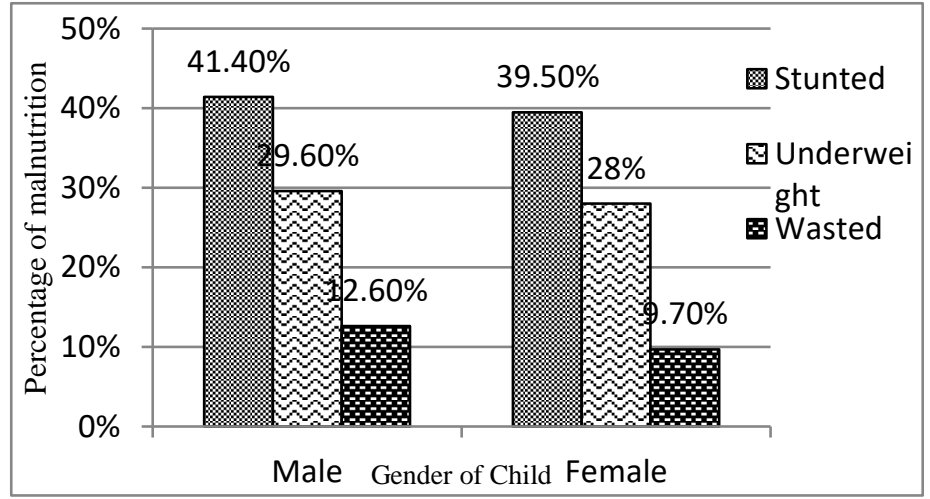

Figure 3: Nutritional status of male and female children

Table1: Nutritional status of under-five year children according to WHO criteria.

Table 1 shows that nutritional status of under five year children according to WHO criteria. From this finding it shows that $16.7 \%$ of the child were severe stunted and $22.8 \%$ were moderate stunted, $2.5 \%$ of the children were severe wasting and $6.4 \%$ of the children were moderate, and $7.7 \%$ of the children were sever underweight, $20.4 \%$ of the children were moderately underweight. Table 2 shows the association between malnutrition (Stunted) and different variables. To find the association chi-square test was applied. The statistically significant association of malnutrition as defined by height -for- age with the following variables: Place of residence, ethnicity, wealth

\begin{tabular}{|c|c|}
\hline \multirow{2}{*}{\multicolumn{2}{|c|}{$\begin{array}{l}\text { Characteristics } \\
\text { Height for age (Stunted) }\end{array}$}} \\
\hline & \\
\hline$<-3$ SD $($ Severe Stunted $)$ & 16.7 \\
\hline$-3 \mathrm{SD} \leq \mathrm{Z}<-2 \mathrm{SD}$ (Moderate Stunted) & 22.8 \\
\hline$-2 \mathrm{SD} \leq \mathrm{Z}<2 \mathrm{SD}$ (Normal) & 58.3 \\
\hline$\geq 2$ SD (Overweight and Obesity) & 1.2 \\
\hline \multicolumn{2}{|l|}{ Weight for Height (Wasted) } \\
\hline$<-3$ SD (Severe Wasting) & 2.5 \\
\hline$-3 \mathrm{SD} \leq \mathrm{Z}<-2 \mathrm{SD}$ (Moderate Wasted) & 6.4 \\
\hline$-2 \mathrm{SD} \leq \mathrm{Z}<2 \mathrm{SD}$ (Normal) & 86.5 \\
\hline$\geq 2$ SD (Overweight and Obesity) & 2.3 \\
\hline \multicolumn{2}{|l|}{ Weight for age (Underweight) } \\
\hline$<-3 \mathrm{SD}$ (Severe Underweight) & 7.7 \\
\hline$-3 \mathrm{SD} \leq \mathrm{Z}<-2 \mathrm{SD}$ (Moderate Underweight) & 20.4 \\
\hline$-2 \mathrm{SD} \leq \mathrm{Z}<2 \mathrm{SD}$ (Normal) & 70.9 \\
\hline$\geq 2 \mathrm{SD}$ (Overweight and Obesity) & 0.5 \\
\hline
\end{tabular}
index and size of child at birth, number of children in home, age of mother, education of mother, smoking habit of mother, ANC checkup, height of mother, BMI of mother. Regarding the place of residence, due to 
Upadhyay et al., Adv. J. Grad. Res.; Vol. 2, Issue 1, pp: 12-24, July 2017

the deficiency of health institution and geographical difficulties the prevalence of malnutrition (stunted) is higher among rural area (45.3\%) as compare to urban areas $(29.1 \%)$ children. Among the ethnicity, dalit children $(51.1 \%)$ are stunted than other ethnic groups. Regarding wealth index, children of poor family $(52.9 \%)$ are stunted as compare to others family.

Table 2: Association between malnutrition (Stunted) and different variables

\begin{tabular}{|c|c|c|c|c|}
\hline \multirow[t]{2}{*}{ Characteristics } & \multicolumn{2}{|c|}{ Malnutrition (HAZ) } & \multirow[t]{2}{*}{$\chi^{2}$} & \multirow[t]{2}{*}{ P-value } \\
\hline & Yes & No & & \\
\hline \multicolumn{5}{|c|}{ Place of Residence } \\
\hline Rural & $843(45.3)$ & 1017(54.7) & 40.73 & $<0.001$ \\
\hline Urban & $138(29.1)$ & $336(70.9)$ & & \\
\hline \multicolumn{5}{|l|}{ Ethnicity } \\
\hline Dalit & $229(51.1)$ & $219(48.9)$ & & \\
\hline Brahmin/Chhetri & $361(40.9)$ & $522(59.1)$ & 25.63 & $<0.001$ \\
\hline Janajati/Newer & $274(39.5)$ & $420(60.5)$ & & \\
\hline Muslim & $47(30.9)$ & $105(69.1)$ & & \\
\hline Other & $70(44.6)$ & $87(55.4)$ & & \\
\hline \multicolumn{5}{|l|}{ Wealth index } \\
\hline Poor & $630(52.9)$ & $561(47.1)$ & & \\
\hline Middle & $167(37.7)$ & $276(62.3)$ & 132.4 & $<0.001$ \\
\hline Rich & $184(26.3)$ & $516(73.7)$ & & \\
\hline \multicolumn{5}{|l|}{ Size of child birth } \\
\hline Small & 242(53.9) & $207(46.1)$ & & \\
\hline Average & $586(40.7)$ & $854(59.3)$ & 37.69 & $<0.001$ \\
\hline Large & $153(34.4)$ & $292(65.6)$ & & \\
\hline \multicolumn{5}{|c|}{ Number of children in home } \\
\hline$\geq 5$ & $168(58.1)$ & 121(41.9) & & \\
\hline $3-4$ & $320(47.4)$ & $355(52.6)$ & 20.24 & $<0.001$ \\
\hline$\leq 2$ & $493(36)$ & $877(64)$ & & \\
\hline \multicolumn{5}{|c|}{ Age of mother at first birth } \\
\hline$<20$ & $50(33.1)$ & 101(66.9) & & \\
\hline $20-29$ & $621(40)$ & $930(60)$ & 59.31 & $<0.001$ \\
\hline$\geq 30$ & $310(49.1)$ & $322(50.9)$ & & \\
\hline \multicolumn{5}{|c|}{ Education of mother } \\
\hline No education & $546(50.6)$ & $534(49.4)$ & & \\
\hline Primary & $204(44.8)$ & $251(55.2)$ & 96.58 & $<0.001$ \\
\hline Secondary & $206(30.9)$ & $461(69.1)$ & & \\
\hline Higher & $25(18.9)$ & 107(81.1) & & \\
\hline \multicolumn{5}{|c|}{ Smoking Habit of mother } \\
\hline Yes & $155(64)$ & $87(36)$ & 53.73 & $<0.001$ \\
\hline No & $826(39.5)$ & $1266(60.5)$ & & \\
\hline \multicolumn{5}{|l|}{ ANC checkup } \\
\hline No & $423(54.4)$ & $354(45.6)$ & 73.614 & $<0.001$ \\
\hline Yes & $558(35.8)$ & 999(64.2) & & \\
\hline \multicolumn{5}{|l|}{ Height of mother } \\
\hline$<145 \mathrm{~cm}$ & $162(60)$ & $108(40)$ & 40.462 & $<0.001$ \\
\hline$\geq 145 \mathrm{~cm}$ & $819(39.7)$ & $1245(60.3)$ & & \\
\hline \multicolumn{5}{|l|}{ BMI of mother } \\
\hline$<18.5 \mathrm{~kg} / \mathrm{m}^{2}$ & $204(50.4)$ & $777(40.3)$ & 13.988 & $<0.001$ \\
\hline$\geq 18.5 \mathrm{~kg} / \mathrm{m}^{2}$ & 201(49.6) & $1152(59.7)$ & & \\
\hline
\end{tabular}


This study revealed that women and children of very poor and poor (low economic status) families have the highest rates of malnutrition. This may be due to food insecurity in these families that negatively impacts the nutritional status of women and children as well as the other household members. Therefore measures should include government action to support the very poor, poor and to bring about rapid economic growth at the national level. To this effect, it is important to develop community-based interventions giving priority to very poor households as a short-term solution. Children who are small in size at birth are stunted (53.9\%) as compare to average and large size at birth. Regarding number of children in home, those families who have more number of children $(\geq 5)$ are more stunted as compare to other, which shows that there is positive relationship between number of children in home and malnutrition (stunted). Literate mothers had less number of stunted children in comparison with illiterate mother, on the basis of present findings; it is recommended educating the primary child-caretakers (mothers) that improve women's awareness of appropriate feeding practices can improve the nutritional status of children, which can be obtained by using multiple interventional strategies. The prevalence of malnutrition (stunted) on children was higher among those mothers who were tobacco product (smoking habit) so, that tobacco product should be avoided from all the community to decrease the rate of malnutrition. The prevalence of stunted in children is less among the adequate ANC checkup mothers ( $\geq 4$ times). Efforts should be made to improve the ANC services during pregnancy period. Place of delivery and care during the delivery are the most important factors associated with malnutrition so, the concerned authority should increase the incentive for promotion of institutional delivery and knowledge on choosing the appropriate age for the pregnancy and nutritional diet during the pregnancy. Regarding height of the mother the prevalence of stunted in children is less among those mother whose height is $\geq 145 \mathrm{~cm}$. The prevalence of stunted in children is less among those mother whose BMI is in normal range.

Table 3 shows the association between malnutrition (wasted) and different characteristics. Regarding wealth index, $12.2 \%$ children of poor family are wasted as compare to others family. Statistically significant variables in wasted were: wealth index, size of the child at birth, education of mother, sex of child, height of mother, BMI of mother, number of children in home and family size. This finding revealed that women and children of very poor or poor (low economic status) households have the highest rates of malnutrition as compare to middle and rich. $14.5 \%$ children who are small in size at birth wasted as compare to average and large size at birth. Literate mothers had less number of wasted children in comparison with illiterate mother, on the basis of present findings; it is recommended educating the primary child-caretakers (mothers) that improve women's awareness of appropriate feeding practices can improve the nutritional status of children, which can be obtained by using multiple interventional strategies. Regarding the sex of children, $12.2 \%$ male children are wasted; this prevalence is a bit high as among girl's children. The prevalence of wasted is high among those children who are born from the less height mother $(<145 \mathrm{~cm})$. Those mother whose BMI is less than $18.5 \mathrm{~kg} / \mathrm{m}^{2} \mathrm{had}$ more number of children wasted. Regarding the number of children in home, that family who had less number of children have low prevalence of wasted, those families who have more number of children $(\geq 5)$ are more wasted as compare to other, which shows that there is positive relationship between number of children in home and malnutrition (stunted). And in small family have less number of children are wasted. So, government should make the plan for small family which helps to decrease the rate of malnutrition. 
Table 3: Association between malnutrition (wasted) and different characteristics as

\begin{tabular}{|c|c|c|c|c|}
\hline \multirow[t]{2}{*}{ Characteristics } & \multicolumn{2}{|c|}{ Malnutrition(WHZ) } & \multirow[t]{2}{*}{$\chi^{2}$} & \multirow[t]{2}{*}{ P-value } \\
\hline & Yes & No & & \\
\hline \multicolumn{5}{|l|}{ Wealth index } \\
\hline Poor & $140(12.2)$ & $389(87.8)$ & & \\
\hline Middle & $54(11.8)$ & $1051(88.2)$ & 8.99 & 0.011 \\
\hline Rich & $54(7.7)$ & $646(92.3)$ & & \\
\hline \multicolumn{5}{|c|}{ Size of child birth } \\
\hline Small & $65(14.5)$ & $384(85.5)$ & & \\
\hline Average & $154(10.7)$ & $1286(89.3)$ & 14.93 & 0.001 \\
\hline Large & $29(6.5)$ & $416(93.5)$ & & \\
\hline \multicolumn{5}{|c|}{ Education of mother } \\
\hline No education & $145(13.4)$ & $935(86.6)$ & & \\
\hline Primary & $46(10.1)$ & $409(89.9)$ & & $<0.001$ \\
\hline Secondary & $48(7.2)$ & $619(92.8)$ & 19.32 & \\
\hline Higher & $9(6.8)$ & $123(93.2)$ & & \\
\hline \multicolumn{5}{|l|}{ Sex of child } \\
\hline Female & $100(8.9)$ & $1022(91.1)$ & & \\
\hline Male & $148(12.2)$ & $1064(87.8)$ & 6.66 & 0.01 \\
\hline \multicolumn{5}{|l|}{ Height of mother } \\
\hline$<145 \mathrm{~cm}$ & $121(17.6)$ & $566(82.4)$ & & \\
\hline$\geq 145 \mathrm{~cm}$ & $164(10)$ & 1483(90) & & $<0.001$ \\
\hline \multicolumn{5}{|l|}{ BMI of mother } \\
\hline$<18.5 \mathrm{~kg} / \mathrm{m}^{2}$ & $166(24.2)$ & $521(75.8)$ & & \\
\hline$\geq 18.5 \mathrm{~kg} / \mathrm{m}^{2}$ & $239(14.6)$ & $1408(85.4)$ & 16.59 & $<0.001$ \\
\hline \multicolumn{5}{|c|}{ Number of children in home } \\
\hline$\geq 5$ & $47(16.3)$ & $242(83.7)$ & & \\
\hline $3-4$ & $75(11.1)$ & $600(88.9)$ & 12.78 & $<0.001$ \\
\hline$\leq 2$ & $126(9.2)$ & $1244(90.8)$ & & \\
\hline \multicolumn{5}{|l|}{ Family size } \\
\hline$\geq 7$ & $106(12.7)$ & $726(87.3)$ & & \\
\hline $5-6$ & $91(11)$ & 740(89) & 10.48 & $<0.001$ \\
\hline$\leq 4$ & $51(7.6)$ & $620(92.4)$ & & \\
\hline
\end{tabular}

**The figure in parenthesis indicates percentage

Table 4 shows the association between malnutrition (Underweight) and different variables. Statistically, significant variables were: place of residence, ethnicity, smoking habit of the mother, place of delivery, wealth index, size of child at birth, education of mother, ANC checkup, age of mother, number of children in home, BMI of mother and height of mother. 
19

Statistical Analysis on Nutritional Status and its Associated Factors of Under Five Years Children in Nepal

Table 4: Association between malnutrition (Underweight) and different variables

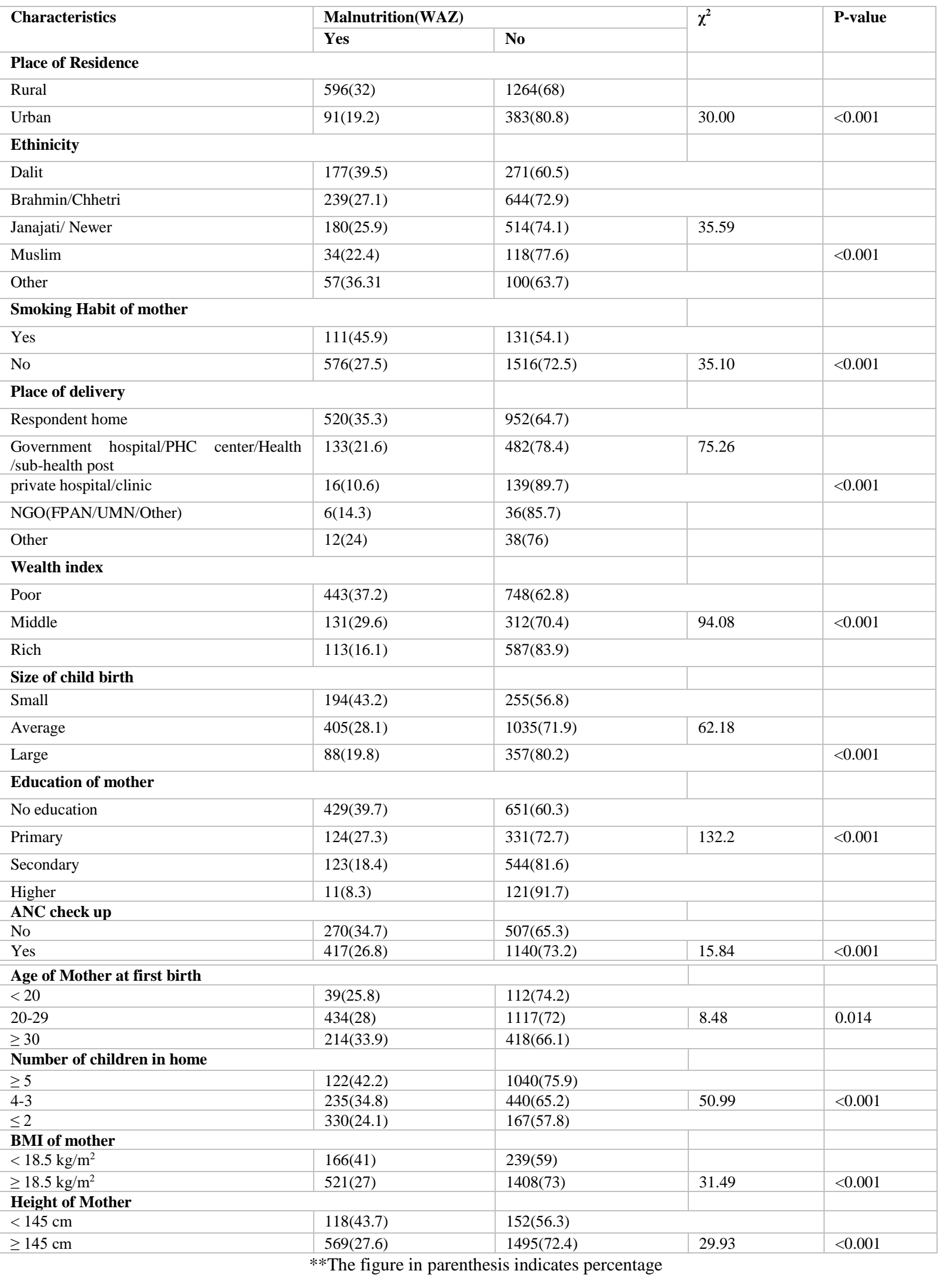


Upadhyay et al., Adv. J. Grad. Res.; Vol. 2, Issue 1, pp: 12-24, July 2017

Regarding the place of residence, due to the deficiency of health institution and geographical difficulties the prevalence of malnutrition (Underweight) is higher among rural area (32\%) as compare to urban areas children. Among the ethnicity, dalit children (39.5\%) are stunted than other ethnic groups, so the emphasis should be given to the poor ethnic groups. The prevalence of malnutrition (Underweight) on children was higher among those mothers who were tobacco product (smoking habit) so, that tobacco product should be avoided from all the community to decrease the rate of malnutrition (Underweight). The prevalence of underweight in children is high among those mothers who are delivery in home. Regarding wealth index, $37.2 \%$ children of poor family are underweight as compare to others family. $43.2 \%$ children who are small in size at birth underweight as compare to average and large size of child at birth. Literate mothers had less number of underweight children in comparison with illiterate mother, on the basis of present findings; it is recommended educating the primary child-caretakers (mothers) that improve women's awareness of appropriate feeding practices can improve the nutritional status (underweight) of children, which can be obtained by using multiple interventional strategies. The prevalence of underweight is less among those children whose mother had visit the adequate ANC checkup ( $\geq 4)$. Those mothers whose age is less than 20 years had more children underweight. The prevalence of underweight is less among those families having less number of children. Regarding the number of children in home, the family having more number of children had more children underweight. Those mother whose BMI is less than $18.5 \mathrm{~kg} / \mathrm{m}^{2}$ had more number of children underweight. The prevalence of underweight is high among those children who are born from the less height mother $(<145$ $\mathrm{cm})$.

\subsection{Test of Multicollinearity}

The presences of multicollinearity within the set of independent variables for stunted, wasted and underweight were determined by using variance inflation factor. Here all variance inflation factors were less than ten so, there doesn't exist multicollinearity between independents variables

\subsubsection{For Stunted}

Binary logistic regressions were used for statistically significant variables. Table 5 shows the output of logistic regression of stunted for different characteristics. Regarding the wealth index, children of middle class mother were 1.69 (with $95 \% \mathrm{CI}=1.31$ to 2.18 ) times stunted as compared to those children who were born by the rich class mother and 2.31 (with 95\% CI $=73$ to 2.98) times as compared to those children who were born by the poor class mother. This result was also found to be statistically significant. Children who were average in size at birth were 1.32 times (with $95 \% \mathrm{CI}=1.00$ to 1.72 ) stunted as compared to those children who were large in size at birth and who are small in size were 1.56 (with $95 \% \mathrm{CI}=1.19$ to 2.04 ) times stunted as compared to those children who were large in size at birth. Children who born from the mother with smoking habit were 1.5 (with $95 \% \mathrm{CI}=1.17$ to 1.91 ) times stunted as compared to those children who were born from the nonsmoking mother. Children who were born from the not ANC checkup mother were 2.18 (with $95 \% \mathrm{CI}=1.83$ to 2.60 ) times stunted as compared to those children who were born from ANC checkup mother. Children who were born from those mother whose height is $<145 \mathrm{~cm}$ were 1.49 (with $95 \% \mathrm{CI}=1.15$ to 1.98 ) times stunted as compared to those children who were born from the mother whose height is greater than or equal to $145 \mathrm{~cm}$. Children who were born from those mother whose BMI is $<18.5 \mathrm{~kg} / \mathrm{m}^{2}$ were 1.47 (with $95 \%$ $\mathrm{CI}=1.14$ to 1.89$)$ times stunted as compare to those children who were born from those mother whose BMI was greater than or equal to $18.5 \mathrm{~kg} / \mathrm{m}^{2}$. 
Table 5: Logistic regression of stunted for different characteristics

\begin{tabular}{|c|c|c|c|c|c|c|}
\hline \multirow[t]{2}{*}{ Characteristics } & \multirow[t]{2}{*}{ B } & \multirow[t]{2}{*}{ SE } & \multirow[t]{2}{*}{ OR } & \multirow[t]{2}{*}{ P-value } & \multicolumn{2}{|c|}{ 95\% C.I. for OR } \\
\hline & & & & & Lower & Upper \\
\hline \multicolumn{7}{|l|}{ Wealth index } \\
\hline \multicolumn{7}{|l|}{ Rich(Ref.) } \\
\hline Middle & 0.3 & 0.14 & 1.69 & $<0.001$ & 1.31 & 2.18 \\
\hline Poor & 0.57 & 0.05 & 2.31 & 0.03 & 1.73 & 2.98 \\
\hline \multicolumn{7}{|c|}{ Size of child at birth } \\
\hline \multicolumn{7}{|l|}{ Large (Ref.) } \\
\hline Average & 0.03 & 0.01 & 1.32 & $<0.001$ & 1.00 & 1.72 \\
\hline Small & -0.25 & 0.12 & 1.56 & 0.04 & 1.19 & 2.04 \\
\hline \multicolumn{7}{|c|}{ Smoking habit of mother } \\
\hline \multicolumn{7}{|l|}{ No (Ref.) } \\
\hline Yes & 0.22 & 0.07 & 1.5 & $<0.001$ & 1.17 & 1.91 \\
\hline \multicolumn{7}{|l|}{ ANC check up } \\
\hline \multicolumn{7}{|l|}{ Yes (Ref.) } \\
\hline No & 0.42 & 0.1 & 2.18 & $<0.001$ & 1.83 & 2.60 \\
\hline \multicolumn{7}{|l|}{ Height of mother } \\
\hline \multicolumn{7}{|l|}{$\geq 145 \mathrm{~cm}$ (Ref.) } \\
\hline$<145 \mathrm{~cm}$ & 0.79 & 0.14 & 1.49 & $<0.001$ & 1.15 & 1.98 \\
\hline \multicolumn{7}{|l|}{ BMI of mother } \\
\hline \multicolumn{7}{|l|}{$\geq 18.5 \mathrm{~kg} / \mathrm{m}^{2}$ (Ref.) } \\
\hline$<18.5 \mathrm{~kg} / \mathrm{m}^{2}$ & 0.27 & 0.12 & 1.47 & 0.02 & 1.14 & 1.89 \\
\hline Constant & -0.45 & 0.23 & 0.64 & 0.05 & & \\
\hline
\end{tabular}

\subsubsection{Model Adequacy Test}

In binary logistic regression Hosmer- Lemeshow test statistic was used for the model adequacy test. For this test a model is said to be poor fit if the p-value is less than 0.05 . Here for stunted chi-square value is 11.61 with 8 degree of freedom and $\mathrm{p}$-value is 0.17 , which implies that there is no significant difference between observed and predicted values indicating that model fit the data at an acceptable level. Strength of logistic regression relationship is computed from the pseudo R-square value. In logistic regression model indication of the amount of variation in the dependent variable is given by Cox \& Snell R-square and Nagelkerker R-square which are described as pseudo R-square. The results in the Table 6 reveals that the value are 0.113 and 0.152 respectively suggesting that between $11.3 \%$ and $15.2 \%$ of the variation in response variable is explained by the set of independent variables used in the model.

Table 6: Pseudo R-Square Value of The Model for Stunted.

\begin{tabular}{|c|c|c|}
\hline -2 Log likelihood & Cox \& Snell R Square & Nagelkerke R Square \\
\hline 2929.57 & 0.113 & 0.152 \\
\hline
\end{tabular}

\subsubsection{For Wasted}

Binary logistic regressions were used for statistically significant variables. Table 7 shows the output of logistic regression of wasted for different characteristics. Children who were average in size at birth were 1.35 times (with $95 \% \mathrm{CI}=1.01$ to 1.83 ) wasted and who were small in size were 2.23 (with $95 \% \mathrm{CI}=1.65$ to 2.99 ) times wasted as compared to those children who were large at birth. Children who were born from the uneducated mother were 1.97 (with $95 \% \mathrm{CI}=1.58$ to 2.44 ) times, from primary were 1.86 (with $95 \% \mathrm{CI}=1.49$ to 3.3) times and from secondary were 1.32 (with $95 \% \mathrm{CI}=0.95$ to 1.63) times underweight as compared to those children who were born from higher education mother but this result was found to be statistically insignificant $(\mathrm{p}-$ value $=0.21)$. Female children were 0.69 times (with $95 \% \mathrm{CI}=0.52$ to 0.89 ) wasted as 
Upadhyay et al., Adv. J. Grad. Res.; Vol. 2, Issue 1, pp: 12-24, July 2017

compared to the male children. Children who were born from those mother whose BMI is $<18.5 \mathrm{~kg} / \mathrm{m}^{2}$ were 1.87 (with $95 \% \mathrm{CI}=1.50$ to 2.31 ) times wasted as compare to those children who were born from those mother whose BMI was greater than or equal to $18.5 \mathrm{~kg} / \mathrm{m}^{2}$.

Table 7: Logistic regression of wasted for different characteristics

\begin{tabular}{|c|c|c|c|c|c|c|}
\hline \multirow[t]{2}{*}{ Characteristics } & \multirow[t]{2}{*}{ B } & \multirow[t]{2}{*}{ S.E. } & \multirow[t]{2}{*}{ P-Value } & \multirow[t]{2}{*}{ OR } & \multicolumn{2}{|c|}{ 95\% C.I. for OR } \\
\hline & & & & & Lower & Upper \\
\hline \multicolumn{7}{|c|}{ Size of child at birth } \\
\hline \multicolumn{7}{|l|}{ Large (Ref.) } \\
\hline Average & 0.08 & 0.05 & $<0.001$ & 1.35 & 1.01 & 1.83 \\
\hline Small & 0.54 & 0.21 & 0.01 & 2.23 & 1.65 & 2.99 \\
\hline \multicolumn{7}{|c|}{ Education of mother } \\
\hline \multicolumn{7}{|c|}{ Higher education (Ref.) } \\
\hline Secondary & 0.22 & 0.18 & 0.21 & 1.32 & 0.95 & 1.63 \\
\hline Primary & 0.61 & 0.17 & $<0.001$ & 1.86 & 1.49 & 3.30 \\
\hline No education & 0.56 & 0.35 & $<0.001$ & 1.97 & 1.58 & 2.44 \\
\hline \multicolumn{7}{|l|}{ Sex of child } \\
\hline \multicolumn{7}{|l|}{ Female (Ref.) } \\
\hline Male & -0.38 & 0.14 & 0.01 & 0.69 & 0.52 & 0.89 \\
\hline \multicolumn{7}{|l|}{ BMI of Mother } \\
\hline \multicolumn{7}{|c|}{$\geq 18.5 \mathrm{~kg} / \mathrm{m}^{2}$ (Ref.) } \\
\hline$<18.5 \mathrm{~kg} / \mathrm{m}^{2}$ & 0.53 & 0.16 & $<0.001$ & 1.87 & 1.50 & 2.31 \\
\hline Constant & 1.73 & 0.18 & $\mathbf{0 . 0 0}$ & 3.63 & & \\
\hline
\end{tabular}

\subsubsection{Model Adequacy Test}

For the model adequacy test in the binary logistic regression, Hosmer- Lemeshow test was used. Here for stunted chi-square value is 3.37 with 8 degree of freedom and p-value is 0.91 , which implies that there is no significant difference between observed and predicted values indicating that model fit the data at an acceptable level. Strength of logistic regression relationship is computed from the pseudo R- square value. Table 8 shows Pseudo R-square value of the model for wasted. The result in the table reveals that the value are 0.024 and 0.049 respectively suggesting that between $2.4 \%$ and $4.9 \%$ of the variation in response variable is explained by the set of independent variables used in the model.

Table 8: Pseudo R-square value of the model for wasted.

\begin{tabular}{|c|c|c|}
\hline $\mathbf{- 2}$ Log likelihood & Cox \& Snell R Square & Nagelkerke R Square \\
\hline 1573.672 & 0.024 & 0.049 \\
\hline
\end{tabular}

\subsubsection{For Underweight}

Binary logistic regressions were used for statistically significant variables. Table 9 shows the output of logistic regression of underweight for different characteristics. Children who were born in the middle-class family were 1.25 (with 95\% CI = 1.15 to 1.63) times underweight and who were born in poor family were 2.31 (with $95 \% \mathrm{CI}=1.76$ to 3.02$)$ times underweight as compared to those children who were born in rich family. Children who born from the smoking habit mother were 1.66 (with $95 \%$ CI $=1.26$ to 2.17) times underweight as compared to those children who were born from the nonsmoking habit mother. Children 
who were average in size at birth were 1.5 times (with $95 \% \mathrm{CI}=1.14$ to 1.97 ) underweight and who were small in size were 2.18 (with 95\% CI $=1.66$ to 2.85) times underweight as compared to those children who were large at birth. Children who were born from the low BMI $\left(<18.5 \mathrm{~kg} / \mathrm{m}^{2}\right)$ mother were 1.51 (with $95 \%$ CI $=1.15$ to 1.98 ) times underweight as compared to children who were born from those mother whose BMI $\geq 18.5 \mathrm{~kg} / \mathrm{m}^{2}$. Children who were born from those mother whose height is less than $145 \mathrm{~cm}$ were 1.58 (with $95 \%$ CI $=1.20$ to 2.07 ) times underweight as compare to those children who were born from those mother whose height is greater than or equal to $145 \mathrm{~cm}$.

Table 9: Logistic regression of underweight for different characteristics

\begin{tabular}{|c|c|c|c|c|c|c|}
\hline \multirow[t]{2}{*}{ Characteristics } & \multirow[t]{2}{*}{ B } & \multirow[t]{2}{*}{ S.E. } & \multirow[t]{2}{*}{ P-Value } & \multirow[t]{2}{*}{ OR } & \multicolumn{2}{|c|}{ 95\% C.I. for OR } \\
\hline & & & & & Lower & Upper \\
\hline \multicolumn{7}{|l|}{ Wealth index } \\
\hline \multicolumn{7}{|l|}{ Rich (Ref.) } \\
\hline Middle & -0.37 & 0.16 & 0.02 & 1.25 & 1.15 & 1.63 \\
\hline Poor & 0.77 & 0.31 & 0.03 & 2.31 & 1.76 & 3.02 \\
\hline \multicolumn{7}{|l|}{ Smoking habit } \\
\hline \multicolumn{7}{|l|}{ No (Ref.) } \\
\hline Yes & 0.35 & 0.15 & 0.02 & 1.66 & 1.26 & 2.17 \\
\hline \multicolumn{7}{|c|}{ Size of child at birth } \\
\hline \multicolumn{7}{|l|}{ Large (Ref.) } \\
\hline Average & 0.12 & 0.03 & 0.001 & 1.5 & 1.14 & 1.97 \\
\hline Small & 0.54 & 0.12 & $<0.001$ & 2.18 & 1.66 & 2.85 \\
\hline \multicolumn{7}{|l|}{ BMI of mother } \\
\hline \multicolumn{7}{|c|}{$\geq 18.5 \mathrm{~kg} / \mathrm{m}^{2}$ (Ref.) } \\
\hline$<18.5 \mathrm{~kg} / \mathrm{m}^{2}$ & -0.44 & 0.12 & $<0.001$ & 1.51 & 1.15 & 1.98 \\
\hline \multicolumn{7}{|c|}{ Height of mother } \\
\hline \multicolumn{7}{|l|}{$\geq 145 \mathrm{~cm}$ (Ref.) } \\
\hline$<145 \mathrm{~cm}$ & -1.59 & 0.13 & $<0.001$ & 1.58 & 1.20 & 2.07 \\
\hline Constant & 0.08 & 0.24 & 0.74 & 1.08 & & \\
\hline
\end{tabular}

\subsubsection{Model Adequacy Test}

For the model adequacy test in the binary logistic regression Hosmer-Lemeshow test was used. Here for stunted Chi-square value is 6.89 with 8 degree of freedom and p-value is 0.55 , which implies that there is no significant difference between observed and predicted values indicating that model fit the data at an acceptable level. Strength of logistic regression relationship is computed from the Pseudo R- square value. Table 10 shows Pseudo R-square value of the model for underweight. In logistic regression model indication of the amount of variation in the dependent variable is given by Cox \& Snell R-square and Nagelkerker Rsquare which are described as pseudo R-square. The result in the table above revels that the value are 0.103 and 0.147 respectively suggesting that between $10.3 \%$ and $14.7 \%$ of the variation in response variable is explained by the set of independent variables used in the model

Table 10: Pseudo R-square value of the model for underweight.

\begin{tabular}{|c|c|c|}
\hline $\mathbf{- 2}$ Log likelihood & Cox \& Snell R Square & Nagelkerke R Square \\
\hline 2589.938 & 0.103 & 0.147 \\
\hline
\end{tabular}


Upadhyay et al., Adv. J. Grad. Res.; Vol. 2, Issue 1, pp: 12-24, July 2017

\section{Conclusions}

This study was focused on finding the prevalence and factors associated with nutritional status of under five year children. The finding of the study shows that the prevalence of stunted, wasted and underweight is high which a major issue of our country. The prevalence of malnutrition is higher among the boys children as compare to the girls children. The prevalence of malnutrition is higher among the children from the mountain region also those who are from the mid-western development region and children in the rural area have poor nutrition as compared to urban area. Factor affecting the nutritional status of children were in stunted (wealth index, size of child at birth, smoking habit of mother, ANC checkup, height of mother and BMI of mother), in wasted (size of child at birth, education of mother, sex of child, BMI of mother) and in underweight (wealth index, smoking habit of mother, size of child at birth, BMI of mother, height of mother). Efforts should be made to improve the ANC services during pregnancy period. Place of delivery and care during the delivery are the most important factors associated with malnutrition so, the concerned authority should increase the incentive for promotion of institutional delivery and knowledge on choosing the appropriate age for the pregnancy and nutritional diet during the pregnancy.

\section{Acknowledgement}

I am indebted to Mr. Madhav Kumar Bhusal, Lecturer of Central Department of Statistics. With great revence, I extend my deep sense of gratitude to my respected teacher Mr. Govinda Prasad Dhungana, Lecturer of Birendra Multiple Campus. I am thankful to Macro International Inc. and New Era for allowing me to use the data from Nepal Demographic and Health Survey, 2011.

\section{How to cite this article:}

Upadhyay, H., \& Bhusal, M. (2017). Statistical Analysis on Nutritional Status and its Associated Factors of Under Five Years Children in Nepal. Advanced Journal of Graduate Research, 2(1), 12-24. doi: https://doi.org/10.21467/ajgr.2.1.12-24

\section{References}

[1] World Bank “World Development Report 2012: Gender Equality and Development” World Bank., 2012.

[2] Ronsmans et, al. "Maternal mortality in Developing countries" Nutrition and Health in Developing Countries. $2^{\text {nd }}$ edition. Humana Press, 2008.

[3] Pradhan, A, "Factors Associated with Nutritional Status of the Under Five Children" Asian Journal of Medical Sciences, vol 1, no 1, pp.6-8, 2010.

[4] Dhungana, G. P,. "Nutritional Status Of Under 5 Children And Associated Factors Of Kunchha Village Development Committee" Journal of Chitwan Medical College, vol 3, no 4, pp38-42, 2013.

[5] WHO Multicentre Growth Reference Study Group. "WHO Child Growth Standards: Length/height-for-age, weight-for-age, weight-forlength, weight-for-height and body mass index-for-age: Methods and development" Geneva: World Health Organization, 2006.

[6] Nepal Demographic and Health Survey. Kathmandu, Nepal: Ministry of Health and Population, New ERA, and ICF International, Calverton, Maryland, pp. 166-173, 2011.

Publish your research article in AIJR journals-

$\checkmark$ Online Submission and Tracking

$\checkmark$ Peer Reviewed

$\checkmark$ Rapid decision

$\checkmark$ Immediate Publication after acceptance

$\checkmark$ Open Access (Articles freely available online)

$\checkmark$ Retain full copyright of your article.

Submit your article at journals.aijr.in 